\title{
PERI-IMPLANT STRAIN WITH LOCATOR AND BAR ATTACHMENT DURING DISLODGING OF MAXILLARY IMPLANT OVERDENTURE. A COMPARATIVE INVITRO STUDY
}

\author{
Shahinaz Sayed Mohamed Hassan* and Mohamad Hossam El-Din Helmy**
}

\begin{abstract}
Purpose:_This study aimed to evaluate Peri-implant strain with locator and bar attachment during dislodging of maxillary implant overdenture

Materials and methods: Four implants were inserted in completely edentulous acrylic maxillary model in canine and premolar areas. Experimental maxillary overdentures with 4 metal hooks were constructed and connected the implants with bar attachments (group I) or locator attachment (group 2). Two strain gauges were bonded at buccal and palatal surface of each implant. Micro strains were measured at buccal and palatal surface of canine and premolar implants during the vertical dislodging of the overdenture. Dislodging was made by chains connected at one end to the metal hooks and to a universal testing machine at the other end.
\end{abstract}

Results: For canine and premolar implants, locator attachment showed significant higher microstrain values than bar attachments at buccal and palatal gauge positions. For bar group, no difference between buccal and palatal strain gauge positions was detected. However, for locator attachments, buccal strain gauges demonstrated significant higher strain than palatal gauges. For buccal and palatal strain gauges, canine implants showed higher strains than premolar implants for both groups

Conclusion: Within the limitation of this in vitro study, could be concluded that bar attachments may be recommended to retain maxillary implant overdentures than locator attachments in terms of reduced peri-implant stresses that occur during the denture dislodgment which may lead to increased bone resorption around the implants.

* Lecturer, Department of Removable Prosthodontics, Faculty of Dentistry, Beni-Suef University, Egypt.

** Lecturer, Department of Removable Prosthodontics, Faculty of Dentistry, Assiut University, Assiut, Egypt 


\section{INTRODUCTION}

Although the survival rate of maxillary implant overdenture is lower than mandibular implant overdenture $^{1-3}$ due to compromised bone quantity and quality, such overdentures are widely used to provide retention and stability of maxillary denture, adequate lip support, enhance phonetics, and improve oral hygiene compared to fixed prosthesis in cases of atrophy of maxilla ${ }^{4,5}$. There appears to be a consensus in the reviewed literature that a minimum of 4 implants is favorable ${ }^{6-9}$. The implants are positioned in premaxilla to avoid sinus floor elevation ${ }^{10,11}$

For maxillary implant overdentures, various attachment can be used including splinting (bar-clip constructions with various bar-shape designs) or not splinting the implants (Locators and attachments with telescopic copings) ${ }^{12}$. The used attachment should allow implant angulation due to inclination of the implants in pre-maxillary region. The bar attachments have several advantages such as splinting implants, wide load distribution, and can be used with divergent implants ${ }^{13}$. Locator attachments are widely used today due to simplicity. Moreover, it is self-aligning, provide several degrees of retention, have increased retention forces attributed to the internal and external friction flanges ${ }^{14}, 15$. Furthermore, it is resilient, can compensate for implant angulation, and it can be easily replaced if the retention decreased ${ }^{14,16}$

With maxillary implant overdentures, implants are subject to high biomechanical forces due to reduced bone quality and quantity, divergent implant axes, and offset positioning of denture teeth, which increase bending moments on implants ${ }^{17,18}$. The attachment design and retention mechanism may significantly influence stress/strain magnitude around implants ${ }^{19}$. Excessive loads applied to the implant may cause pathologic stresses and strains in the crestal bone stimulating resorption ${ }^{20}$. Enhanced overdenture retention and stability have been identified as the most important factors for producing more favorable overdenture treatment outcome and improved patient satisfaction and oral health related quality of life ${ }^{21}$. On the other hand, very high retention forces may induce load on implants during overdenture dislodgement or when removing the overdenture ${ }^{22}$. Therefore, a compromise should be made between high retention force vs. peri-implant stress ${ }^{22,23}$

Reviewing the literature, many invitro reports ${ }^{24-26}$ evaluated the retention forces of maxillary implant overdenture attachments. Other invitro studies ${ }^{27,28}$ investigated the effect of attachment type on periimplant stresses. However, the evaluation of periimplant stresses associated with different attachments during overdenture dislodging was scare and limited to mandibular overdentures only ${ }^{29,30}$. The purpose of this invitro investigation was to study strain around implants with locator and bar attachment during dislodging of maxillary implant overdenture using strain gauge measurements. The null hypothesis is no difference in peri-implant strain between the attachments will be obtained.

\section{MATERIALS AND METHODS}

\section{Fabrication of test model}

A completely edentulous acrylic resin maxillary model that has no ridge undercuts and has adequate with bone quantity was constructed. Four implant fixtures $(3.6 \times 12 \mathrm{~mm}$, Dentium, Korea) were inserted in the maxillary anterior region canine and premolar areas using sequential drilling was acrylic bur $^{26}$. Posterior implants were oriented vertically and anterior implants were oriented with slight labial inclination due to the anatomy of premaxillary region. The implants were fixed to the acrylic holes with self-cure acrylic resin to simulate osteointegration. The residual alveolar ridge and palatal areas of the model was covered with 2 millimeter with thickness resilient liner (Elite Super Soft, Zhermack, Badia Polesine, Italy) to mimic the palatal mucosa ${ }^{31,32}$. The locator and bar and abutments were threaded to implant using torque wrench at $30 \mathrm{Ncm}$. 
For bar group, 4 plastic bar abutments where connected to the abutments. The plastic resin of prefabricated Hader bar joint (Rhein, Italy) was luted to the plastic Caps. The resin bar was sectioned to 5 segments (one segment was fixed between canines, 2 segments were fixed between canines and the premolars and two segments were used as distal cantilevers (9mm length). All segments were oriented in the same vertical plane leaving $1.5 \mathrm{~mm}$ space below the bar for oral hygiene. ${ }^{33-35}$. The plastic bar was cast in cobalt-chromium alloy. Four yellow plastic clips (medium retention) were positioned on the bar segments ( 2 in the anterior segment, 2 in the premolar segment and no clips were positioned on the cantilevers). For Locator group, blocking ring were snapped over locator abutments. Locator metal housings with processing inserts were positioned on the abutments (fig 1).
For each attachment, an experimental overdenture was fabricated (fig2). The overdenture is consisted of metal framework and acrylic resin occlusion rim. A duplicate impression was made for each attachment and poured with stone and investment to make master and refractory models. Over the investment model, cobalt-chromium metallic framework that cover the edentulous ridge was fabricated with four metal hooks attached to canine and second molar areas ${ }^{35}$. The metal framework was positioned over the master cast and acrylic resin denture base with occlusion rim was constructed using heat cure acrylic resin. Over the acrylic models, one experimental overdenture was connected to the bar clips and the other experimental overdenture was connected to the metal housing of the locators using self-cure acrylic resin. Locator medium retention, (pink inserts) were used.

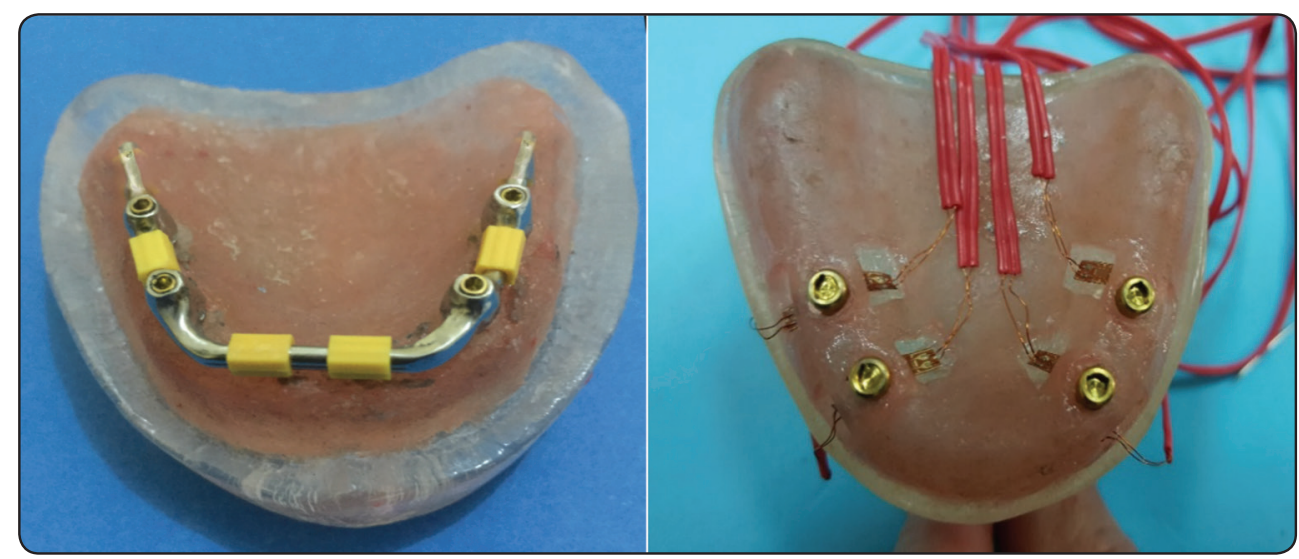

Fig. (1) (A) Hader bar group, (B) locator attachment group.

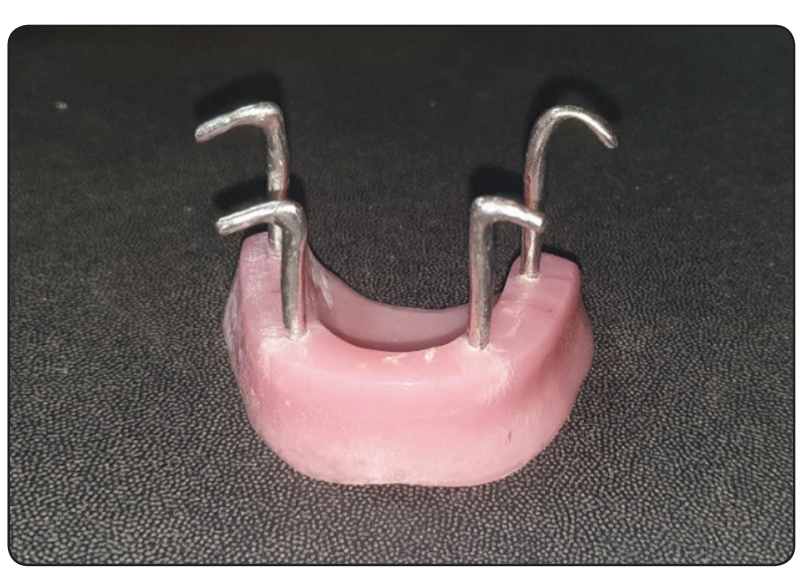

Fig. (2) Experimental overdentures with metal framework and acrylic resin rim

\section{Strain gauge measurements}

On the acrylic model, the resilient liner attachment was removed around each implant from buccal and palatal areas to provide room for strain gauge fixation. 4 strain gauges (KYOWA, Japan) were bonded to buccal and palatal areas of cast around implants ${ }^{36}$ using a bonding agent provided by the manufacturer. The long axis of gauges was oriented with the axis of the implants (fig 1B). The wire ends of the gauge were connected to a $1 / 2$ circuit Wheatstone bridge, and to a strain measuring device (Tinsley, London) that is guided by a software which convert the output voltage to microstrain data. 
Four chains were attached to the to hooks at one end and to a metal plate at the other end ${ }^{37}$. The plate was connected to a testing device. Vertical dislodging force was exerted at $50 \mathrm{~mm} / \mathrm{min}$ speed till complete dislodging of the overdenture from the model ${ }^{37,38}$. Measurement of periimplant strain ( $\mu$ microstrain) at buccal and palatal strain gauges was made during the vertical dislodgment (fig3). The measurements we repeated three times and mean was used for statistical analysis.

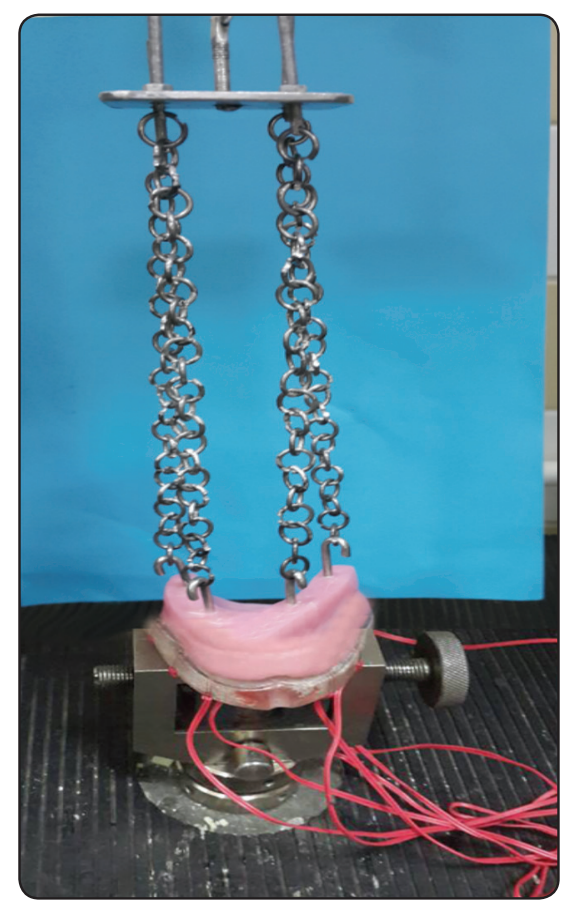

Fig. (3) Measurements of strain during overdenture dislodging

\section{Statistical analysis}

SPSS software version 22 (SPSS Inc.) was used to analyze the data. The normality of data distribution was tested by Shapiro wilk test. Independent sample t-test was used to compare recorded $\mu$ microstrain values between groups, stating gauge positions and implant locations (canine and premolar implants). $\mathrm{P}<.05$ was significant.

\section{RESULTS}

Before measurement, calibration of strain gauges was performed. The aim of the calibration was to ensure that all measurements are reliable and that all strain gauges read a repeatable measurement. To study the relation between applied force and resultant strain, a vertical load was applied to the overdenture from 0 to 60 Newton $(10,20,30,40$, 50 and $60 \mathrm{~N}$ ) and strain for each load was recorded. A verification of linear relationship between applied force and resultant strain was made.

At All microstrain data are normal distributed and are presented as mean and standard deviation. Extreme values were removed to avoid violation of normal distribution of the data. Comparison of microstrains between groups and strain gauge positions are presented in table 1. For canine implants, locator attachment showed significant higher microstrain values than bar attachments at buccal and palatal gauge positions. Comparison of buccal and palatal strain gauges is presented in the same table. There is no significant difference between buccal and palatal strain gauges for both groups. Regarding premolar implants, also locator attachments showed significant higher microstrain values than bar attachments for both palatal and the buccal strain gauge positions. For bar group, no difference between buccal and palatal stating gauge positions was detected. However, for locator attachments, buccal strain gauges demonstrated significant higher strain than palatal gauges.

Comparison of microstrain values between canine and premolar implants for buccal and palatal strain gauge positions is presented in figure 4 and 5 respectively. For buccal strain gauges, canine implants showed significant higher strain magnitude than premolar implants for bar $(\mathrm{p}=.009)$ and locator $(p=.023)$ attachments. For palatal strain gauges, canine implants showed significant higher strain magnitude than premolar implants for bar $(\mathrm{p}=.012)$ and locator $(\mathrm{p}=.001)$ attachments. 
TABLE (1) Comparison of microstrain between groups and strain gauge positions

\begin{tabular}{|c|c|c|c|c|c|}
\hline & \multicolumn{2}{|c|}{ Bar } & \multicolumn{2}{|c|}{ Locator } & $P$ value \\
\hline & \multicolumn{5}{|c|}{ Canine implants } \\
\hline & Mean & SD & Mean & SD & \\
\hline Buccal & 57.50 & 5.00 & 82.00 & 13.04 & $.007 *$ \\
\hline Palatal & 52.40 & 15.21 & 81.00 & 15.84 & $.006 *$ \\
\hline \multirow[t]{3}{*}{ p value } & \multicolumn{2}{|c|}{.56} & \multicolumn{2}{|c|}{.45} & \\
\hline & \multicolumn{5}{|c|}{ Premolar implants } \\
\hline & Mean & SD & Mean & SD & \\
\hline Buccal & 30.00 & 3.54 & 64.00 & 14.75 & $.002 *$ \\
\hline Palatal & 35.00 & 15.25 & 40.00 & .11 & $.049 *$ \\
\hline p value & \multicolumn{2}{|c|}{.47 } & \multicolumn{2}{|c|}{$.024 *$} & \\
\hline
\end{tabular}

*p is significant at $5 \%$.

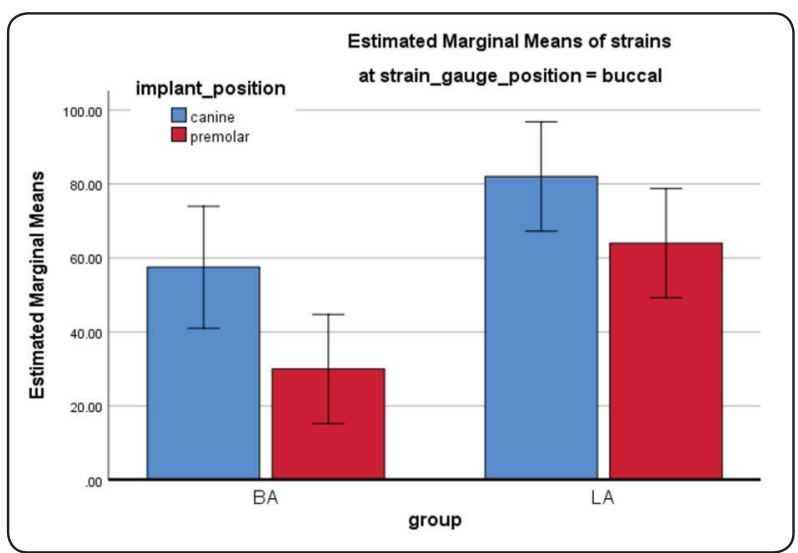

Fig. (4) Comparison of microstrain between implant positions at buccal strain gauges

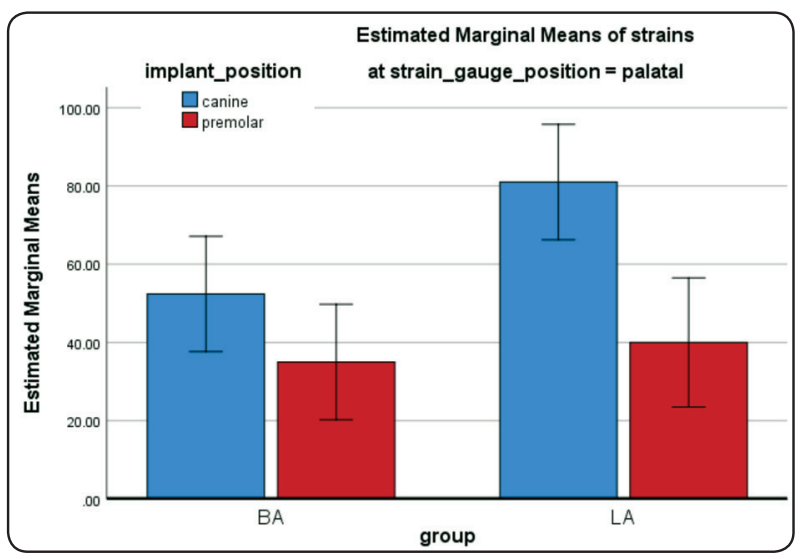

Fig. (5) Comparison of microstrain between implant positions at palatal strain gauges

\section{DISCUSSION}

In this study, 2 gauges were attached to the buccal and palatal surface of each implant and no mesial and the distal gauges were used. This is because not enough space at mesial surface of premolar implant and distal surface of canine implants to mount strain gauges due to close proximity of the implants to each other. Four metal chains connected at canine and second molar teeth and attached to the center of metal plate was used to apply vertical dislodging forces. Before dislodging, care was exercised to make sure is that all chains we are connected without slackness. This method ensures vertical dislodging of the overdenture as one unit without rotation. This method was designed and verified for accuracy in several previous in vitro studies for maxillary and mandibular overdentures ${ }^{24-26,31,35,37-39}$. Vertical dislodging force was exerted at $50 \mathrm{~mm} / \mathrm{min}$ speed to simulate the velocity of overdenture removal from the tissue during chewing as reported in previous studies ${ }^{37,40}$.

For canine and premolar implants, locator attachment showed significant higher microstrain values than bar attachments at buccal and palatal gauge positions during application of vertical dislodging forces. The decreased stresses with bar attachments may be due to the splinting effect of the bar to the implants and greater surface area provided by bar which reduces implant micromotion ${ }^{41}$. The plastic clips transmit the forces indirectly to the implants through bar segments. On the other hand, locator is individual attachments and the subject the implants to more load ${ }^{42,43}$. Another explanation of increased strain was locator attachments is the increased retention forces provided by the double friction flanges of each locator attachments which provide internal and external retention behave like guiding planes and restrict lateral movement of the prosthesis. The increased retention of locator attachments comes from the large size of inserts and the small diameter of abutments ${ }^{44}$. This increased the retention may transmit more stresses to the implants during the dislodging ${ }^{45-47}$. Moreover, the abutment is parallel to the path of removal of the locator inserts, thus 
retention is driven from all the abutments undercut. Thus, the locators did not disconnect easily and transmit increased strains to the implants ${ }^{29}$. Considering that, the choice of ideal attachment should provide sufficient the retention but should apply reduced load to the implants during the denture removal by the patient ${ }^{48}$, bar attachments for maxillary overdentures may be recommended then locator attachments in terms of reduced periimplant stresses that may lead to increased bone resorption around the implants. In line with the results of the study, rigid bars were reported to give good load distribution to the implants ${ }^{42,49}$. The peri-implant stress from splinting (bar) attachment, was found to be lower than that of unsplinted attachment, such as ball anchors ${ }^{50,51}$. In agreement with our observation, Locators are associated with increased retention and peri-implant stress compared to the Hader bar-and-clip attachment when these attachments are used to retain auricular prosthesis as reported by another author ${ }^{22}$

For locator attachments of premolar implants only, buccal strain gauges demonstrated significant higher strain than palatal gauges. This may be due to the deformation of maxillary implant overdenture away from the midline when load is applied ${ }^{52}$, indicating that implants were predominantly strained from palatal to buccal ${ }^{28}$. This pattern of denture deformation together with the increased retention of locator attachments may cause movement of the premolar implants to the buccal direction. Therefore, compression of acrylic resin on the buccal side of premolar implants may occur and could be responsible for increased stresses in the buccal side of premolar implants than palatal side.

For both groups and strain gauge positions canine implant recorded significant higher strain than premolar implants during the dislodging. This may be due to canine implants in the model are slightly inclined labially due to the inclination of premaxillary bone. The dislodging the forces are applied toward the center of maxillary overdenture. Therefore, the dislodging forces are applied at an angle to canine implants which may increase stresses around these implants. On the other hand, premolar implants are located near the center of the denture. Therefore, the dislodging forces are applied to the long axis of premolar implants with rapid disconnection of the attachments from premolar implants. The locator at canine implants are inclined to slightly labially and he may create labial undercuts with nylon inserts during dislodging. Similarly, in bar group, 2 clips are attachment to the bar segment between canine implants and one clip attachment between canine and the premolar implant. This cause increased retention in the area of canines compared to premolars during dislodging which may increase the stresses on canine implants compared to premolar implants.

The limitation of this study includes the absence of simulation of nonaxial dislodging forces which may occur during the denture was working removal by the patient. Also, the absence of saliva may influence the friction between the attachment of components, which may influence the retentive force and consequently the resultant strain 53

\section{CONCLUSION}

Within the limitation of this study, it could be concluded that bar attachments may be recommended to retain maxillary implant overdentures than locators regarding reduced peri-implant stresses that occur during the denture dislodgment which may lead to increased bone resorption around the implants.

\section{REFERENCES}

1. Bergendal T, Engquist B. Implant-supported overdentures: a longitudinal prospective study. Int J Oral Maxillofac Implants. 1998;13:253-62.

2. Jemt T, Chai J, Harnett J, Heath MR, Hutton JE, Johns RB et al. A 5-year prospective multicenter follow-up report on overdentures supported by osseointegrated implants. Int J Oral Maxillofac Implants. 1996;11:291-8.

3. Johns RB, Jemt T, Heath MR, Hutton JE, McKenna S, McNamara DC et al. A multicenter study of overdentures supported by Branemark implants. Int J Oral Maxillofac Implants. 1992;7:513-22. 
4. Fanuscu MI, Caputo AA. Influence of attachment systems on load transfer of an implant-assisted maxillary overdenture. J Prosthodont. 2004;13:214-20.

5. Visser A, Raghoebar GM, Meijer HJ, Vissink A. Implantretained maxillary overdentures on milled bar suprastructures: a 10-year follow-up of surgical and prosthetic care and aftercare. Int J Prosthodont. 2009;22:181-92.

6. Lewis S, Sharma A, Nishimura R. Treatment of edentulous maxillae with osseointegrated implants. J Prosthet Dent. 1992;68:503-8.

7. Mericske-Stern R. Treatment outcomes with implantsupported overdentures: clinical considerations. J Prosthet Dent. 1998;79:66-73.

8. Naert I, Gizani S, van Steenberghe D. Rigidly splinted implants in the resorbed maxilla to retain a hinging overdenture: a series of clinical reports for up to 4 years. J Prosthet Dent. 1998;79:156-64.

9. Kiener P, Oetterli M, Mericske E, Mericske-Stern R. Effectiveness of maxillary overdentures supported by implants: maintenance and prosthetic complications. Int J Prosthodont. 2001;14:133-40.

10. Misch CE. Treatment Options for Mandibular Implant Overdentures in: Misch CE, Bidez MW, Judy KWM et al, eds Dental implant prosthetics. 3nd ed St Louis: Mosby. 2005:218-35.

11. Sadowsky SJ. Treatment considerations for maxillary implant overdentures: a systematic review. J Prosthet Dent. 2007;97:340-8.

12. Barao VA, Assuncao WG, Tabata LF, de Sousa EA, Rocha EP. Effect of different mucosa thickness and resiliency on stress distribution of implant-retained overdentures-2D FEA. Comput Methods Programs Biomed. 2008;92:213-23.

13. Carpentieri JR. Clinical protocol for an overdenture bar prosthesis fabricated with CAD/CAM technology. Pract Proced Aesthet Dent. 2004;16:755-7.

14. Chung KH, Chung CY, Cagna DR, Cronin RJ, Jr. Retention characteristics of attachment systems for implant overdentures. J Prosthodont. 2004;13:221-6.

15. Evtimovska E, Masri R, Driscoll CF, Romberg E. The change in retentive values of locator attachments and hader clips over time. J Prosthodont. 2009;18:479-83.

16. Kleis WK, Kammerer PW, Hartmann S, Al-Nawas B, Wagner W. A comparison of three different attachment systems for mandibular two-implant overdentures: oneyear report. Clin Implant Dent Relat Res. 2010;12:209-18.

17. Carlson B, Carlsson GE. Prosthodontic complications in osseointegrated dental implant treatment. Int J Oral Maxillofac Implants. 1994;9:90-4.
18. Akca K, Akkocaoglu M, Comert A, Tekdemir I, Cehreli MC. Human ex vivo bone tissue strains around immediately loaded implants supporting maxillary overdentures. Clin Oral Implants Res. 2005;16:715-22.

19. Tokuhisa M, Matsushita Y, Koyano K. In vitro study of a mandibular implant overdenture retained with ball, magnet, or bar attachments: comparison of load transfer and denture stability. Int J Prosthodont. 2003;16:128-34.

20. Isidor F. Influence of forces on peri-implant bone. Clin Oral Implants Res. 2006;17 Suppl 2:8-18.

21. Burns DR, Unger JW, Coffey JP, Waldrop TC, Elswick RK, Jr. Randomized, prospective, clinical evaluation of prosthodontic modalities for mandibular implant overdenture treatment. J Prosthet Dent. 2011;106:12-22.

22. Williams BH, Ochiai KT, Baba T, Caputo AA. Retention and load transfer characteristics of implant-retained auricular prostheses. Int J Oral Maxillofac Implants. 2007;22:366-72.

23. Ochiai KT, Williams BH, Hojo S, Nishimura R, Caputo AA. Photoelastic analysis of the effect of palatal support on various implant-supported overdenture designs. J Prosthet Dent. 2004;91:421-7.

24. ELsyad MA, Elhaddad AA, Khirallah AS. Retentive Properties of O-Ring and Locator Attachments for ImplantRetained Maxillary Overdentures: An In Vitro Study. J Prosthodont. 2016; doi: 10.1111/jopr.12534. .

25. ELsyad MA, Emera RM, Ashmawy TM. Effect of Different Bar Designs on Axial and Nonaxial Retention Forces of Implant-Retained Maxillary Overdentures: An In Vitro Study. Int J Oral Maxillofac Implants. 2019;34:31-8.

26. ELsyad MA, Soliman TA, Khalifa AK. Retention and Stability of Rigid Telescopic and Milled Bar Attachments for Implant-Supported Maxillary Overdentures: An In Vitro Study. Int J Oral Maxillofac Implants. 2018;33:e127-e33.

27. Kazokoglu FS, Akaltan F. Strain characteristics of Marburg double crown-retained implant overdentures compared with bar and ball-retained implant overdentures, with and without a rigid major connector. J Prosthet Dent. 2014;112:1416-24.

28. Takahashi T, Gonda T, Maeda Y. Effect of Attachment Type on Implant Strain in Maxillary Implant Overdentures: Comparison of Ball, Locator, and Magnet Attachments. Part 1. Overdenture with Palate. Int J Oral Maxillofac Implants. 2017.

29. Alameldeen HE, Elsyad MA, Shawky AF, Khirallah AS. The Influence of Implant Inclination on Retention and Peri-implant Stresses of Stud-Retained Implant Overdentures During Axial and Nonaxial Dislodgments: An In Vitro Study. Int J Oral Maxillofac Implants. 2020;35:543-50. 
30. Elkerdawy MW, Radi IA. Effect of dislodging forces on mandibular implant attachment-retained overdenture. Implant Dent. 2011;20:246-54.

31. Elsyad MA, Agha NN, Habib AA. Retention and stability of implant retained mandibular over dentures using different types of resilient attachments. An invitro study. Int J Oral Maxillofac Implants. 2016;31:1040-8.

32. ELsyad MA, Omran AO, Fouad MM. Strains Around Abutment Teeth with Different Attachments Used for Implant-Assisted Distal Extension Partial Overdentures: An In Vitro Study. J Prosthodont. 2015:doi: 10.1111/ jopr.12370. [Epub ahead of print].

33. Elsyad MA, Alokda MM, Gebreel AA, Hammouda NI, Habib AA. Effect of two designs of implant-supported overdentures on peri-implant and posterior mandibular bone resorptions: a 5-year prospective radiographic study. Clin Oral Implants Res. 2016.

34. Elsyad MA, Al-Mahdy YF, Salloum MG, Elsaih EA. The effect of cantilevered bar length on strain around two implants supporting a mandibular overdenture. Int J Oral Maxillofac Implants. 2013;28:e143-50.

35. ELsyad MA, Dayekh MA, Khalifa AK. Locator Versus Bar Attachment Effect on the Retention and Stability of Implant-Retained Maxillary Overdenture: An In Vitro Study. J Prosthodont. 2019;28:e627-e36.

36. ELsyad MA, Elsaadawy MG, Abdou AM, Habib AA. Effect of different implant positions on strain developed around four implants supporting a mandibular overdenture with rigid telescopic copings. Quintessence Int. 2013;44:679-86.

37. ELsyad MA, Emera RM, Ashmawy TM. Effect of Distal Implant Inclination on Dislodging Forces of Different Locator Attachments Used for Mandibular Overdentures: An In Vitro Study. J Prosthodont. 2019;28:e666-e74.

38. ELsyad MA, Abo Hatem OE, Shawky AF, Emera RMK. Effect of Different Degrees of Mesial Implant Inclination on the Retention and Stability of Two-Implant Mandibular Overdentures Retained with Stud Attachments: An In Vitro Study. Int J Oral Maxillofac Implants. 2018;33:259-68.

39. ELsyad MA, Emera RM, Ibrahim AM. Effect of Labial Implant Inclination on the Retention and Stability of Different Resilient Stud Attachments for Mandibular Implant Overdentures: An In vitro Study. Int J Oral Maxillofac Implants. 2019;34:381-9.

40. Sarnat AE. The efficiency of cobalt samarium (Co5Sm) magnets as retention units for overdentures. J Dent. 1983;11:324-33.

41. Krennmair G, Krainhofner M, Piehslinger E. Implantsupported mandibular overdentures retained with a milled bar: a retrospective study. Int J Oral Maxillofac Implants. 2007;22:987-94

42. Mericske-Stern R, Piotti M, Sirtes G. 3-D in vivo force measurements on mandibular implants supporting overdentures. A comparative study. Clin Oral Implants Res. 1996;7:387-96.

43. Misch CE, Wang HL, Misch CM, Sharawy M, Lemons J, Judy KW. Rationale for the application of immediate load in implant dentistry: part II. Implant Dent. 2004;13:310-21.

44. Alsabeeha N, Atieh M, Swain MV, Payne AG. Attachment systems for mandibular single-implant overdentures: an in vitro retention force investigation on different designs. Int J Prosthodont. 2010;23:160-6.

45. Elsyad MA, Abid KS, Elkhalek EA. Effect of Buccal Implant Inclination on Stresses Around Two-Implant-Retained Overdentures with Resilient Stud Attachments. Int J Oral Maxillofac Implants. 2017;32:e135-e42.

46. Elsyad MA, Eltowery SM, Gebreel AA. Peri-implant strain around mesially inclined two implants retaining mandibular overdentures with Locator attachments. . J Oral Sci. 2017:(in press).

47. ELsyad MA, Setta FA, Khirallah AS. Strains around distally inclined implants retaining mandibular overdentures with Locator attachments. An in vitro study. The journal of advanced prosthodontics. 2016;8 116-24

48. Yang TC, Maeda Y, Gonda T, Kotecha S. Attachment systems for implant overdenture: influence of implant inclination on retentive and lateral forces. Clin Oral Implants Res. 2011;22:1315-9.

49. Mericske-Stern R, Zarb GA. In vivo measurements of some functional aspects with mandibular fixed prostheses supported by implants. Clin Oral Implants Res. 1996;7:153-61.

50. Naert I, Alsaadi G, van Steenberghe D, Quirynen M. A 10year randomized clinical trial on the influence of splinted and unsplinted oral implants retaining mandibular overdentures: peri-implant outcome. Int J Oral Maxillofac Implants. 2004; 19:695-702.

51. Naert I, Gizani S, Vuylsteke M, van Steenberghe D. A 5-year randomized clinical trial on the influence of splinted and unsplinted oral implants in the mandibular overdenture therapy. Part I: Peri-implant outcome. Clin Oral Implants Res. 1998;9:170-7.

52. Takahashi T, Gonda T, Maeda Y. The influence of reinforcement on strain in maxillary complete dentures: a preliminary report. Int J Prosthodont. 2011;24:273-6.

53. Kobayashi M, Srinivasan M, Ammann P, Perriard J, Ohkubo $\mathrm{C}$, Muller $\mathrm{F}$ et al. Effects of in vitro cyclic dislodging on retentive force and removal torque of three overdenture attachment systems. Clin Oral Implants Res. 2014;25:426-34. 